\title{
Working together? Parent and local authority views on the process of obtaining appropriate educational provision for children with autism spectrum disorders
}

Article

Accepted Version

Tissot, C. (2011) Working together? Parent and local authority views on the process of obtaining appropriate educational provision for children with autism spectrum disorders.

Educational Research, 53 (1). pp. 1-15. ISSN 1469-5847 doi: https://doi.org/10.1080/00131881.2011.552228 Available at https://centaur.reading.ac.uk/17958/

It is advisable to refer to the publisher's version if you intend to cite from the work. See Guidance on citing.

To link to this article DOI: http://dx.doi.org/10.1080/00131881.2011.552228

Publisher: Routledge

All outputs in CentAUR are protected by Intellectual Property Rights law, including copyright law. Copyright and IPR is retained by the creators or other copyright holders. Terms and conditions for use of this material are defined in the End User Agreement. 


\section{www.reading.ac.uk/centaur}

\section{CentAUR}

Central Archive at the University of Reading

Reading's research outputs online 


\title{
Working Together? Parent and Local Authority views on appropriate educational provision for children with autism spectrum disorders
}

\author{
Abstract: \\ Background: There is general agreement across all interested stakeholders that a process of \\ working together is the best way to determine which school or educational setting is right for an \\ individual child with autism spectrum disorder. In the UK, families and Local Authorities both \\ desire a constructive working relationship and see this as important in reaching an agreement to \\ determine where a child should be educated. Although all parties agree this is the goal, the \\ reality is often something less perfect.
}

Purpose: This paper aims to explore the views of both parents and Local Authorities on how they perceive and experience the process of determining educational provision within an English context.

Sample: Parental opinion was gathered through the use of a mixed methods questionnaire. After addressing ethical issues, a questionnaire was distributed with permission to two national charities, two local charities and 16 specialist schools to distribute to parents of children with ASD, resulting in an opportunity sample of 738 returned surveys (representing an estimated $34.3 \%$ rate of return). The view of Local Authority officials was gathered through the use of semi structured interviews. The ten Local Authorities with the greatest number of survey responses to the parental questionnaire were approached and five granted permission (two were Local Authorities in greater London, two in South East and one in the South West).

Results: In the majority of cases, parents obtained their first choice placement. Despite this positive outcome, conclusions show that parents found the process bureaucratic, stressful and time consuming. Any alternative placement suggestions were viewed to be for financial reasons only. Local Authorities are aware of these concerns and during the interviews shared their efforts to address this. They cited the complicated considerations necessary to determine what is best for an individual child and often struggle with conflicting tensions between the goals of inclusion and the merits of individual settings.

Conclusions: A closer look at the process of communication is recommended to ensure that both groups understand the complex considerations needed to be fully informed about alternative choices in educational placements.

Key words: educational provision, autism, parent and local authority views 
Working Together? Parent and Local Authority views on appropriate educational provision for children with autism spectrum disorders

Kanner's (1943, p. 250) description of 'autistic disturbances of affective contact' has had a significant impact on individuals and families of children with autism spectrum disorder, but also on the systems and services which support these individuals. Kanner's article identified what was once seen as a relatively rare disorder (.7 in 10,000 (Treffert, 1970, p. 250)) and over time has grown to a condition that is much more prevalent that previously thought. Recent prevalence figures show this to be 116 in 10,000 in the UK (Baird et al., 2006) as well as the rest of the world (Rice, 2009). This increase may be real, indicating an increase in the number of individuals with autism; or perceived, showing better awareness and diagnosis (Croen, Grether, Hoogstrate, \& Selvin, 2002). What is undisputed is the impact that increasing numbers of individuals are having on educational practice and recent developments in Special Educational Needs provision more broadly. In particular, this paper will focus on the decision making process that happens when an increasing number of children with autism reach school age and families are looking for educational provision.

Educating children with autism alongside their neighbourhood peers in mainstream settings is seen as one solution to the increasing numbers, and is recognised worldwide as a positive strategy (UNESCO, 1994). This practice is well embedded internationally (for example IDEA in the United States ("No Child Left Behind Act," 2007)) and universally accepted on a philosophical basis (Norwich, 2008). The tension comes when implementing inclusion on an individual basis (Croll \& Moses, 2000; J. Evans \& Lunt, 2002). The pressure for inclusion on the part of schools and governing bodies can be at odds with families (Wedell, 2008) who may see expensive specialist (often segregated) provision as the best way to educate their child with autism spectrum disorder. How is this conundrum resolved?

Actively engaging all stakeholders to work together in educating children with additional learning needs is seen as one solution and a positive move towards successful inclusion of these learners in mainstream settings (Mittler, 2008). International research shows the particular value of working with families as '...students achieve more, stay in school longer and engage in school more completely'(Ferguson, 2008, p. 116). As recognition of the importance of this, UK government policies are striving to embed the role of parents into standard practice and increase 
input from parents in the education of their child (DCSF, 2009). Systemic changes have been implemented and are evidenced in key guidance documents for schools, governing bodies and Local Authorities in this area.

In the UK, a major influence on school practice for SEN is the Revised Code of Practice (DFES, 2001). Issued by the UK Department for Education, it established standardised procedures for assessing and implementing support for learners. A period of assessment typically leads to agreement among parents and professionals on the place and specific type of support given. This can take the form of teacher or school based support (School Action, School Action Plus) or for children with significant needs, a Statement is issued. This happens when the Local Authority considers that the 'special educational provision necessary to meet the child's needs cannot reasonably be provided within the resources normally available ...' (DfES, 2001, p. 55). The Statement is a key factor in determining provision for learners with more severe special needs as it outlines specific types of support that is to be provided and is often needed for specialist settings (outside Local Authority remit) or to secure additional staff resources. Because of this, parents often feel that obtaining one for their child is a primary goal.

Another important aspect of the Code of Practice (DfES, 2001) is its emphasis on partnership between schools, Local Authorities and parents. The Code of Practice (2001) states that partnership with parents is '...important in enabling children and young people with SEN to achieve their potential' (p. 16). Parents are seen as an important part of the team that make decisions on provision and are recognised as partners in this process. 'Partnership with parents plays a key role... [and] is important in enabling children and young people with SEN to achieve their potential'(DfES, 2001 p. 16). This is not a disputed point and many schools work hard to welcome parents and consequently benefit directly from actively engaging with this group. However this is not the case universally (Spann, Kohler, \& Soenksen, 2003) and despite this focus, a tension is still perceived on the part of many parents between the desire for inclusive educational practice for their child and the reality in practice. Parents find obtaining appropriate educational provision stressful and are growing increasingly dissatisfied with the process as well as the challenges that mainstream provision presents (Rogers, 2007). This is particularly true for families of children with autistic spectrum disorders (Plant \& Sanders, 2007; Schieve, Blumberg, Rice, Visser, \& Boyle, 2007). 
In addition to research literature, other evidence demonstrates the difficulties faced in reaching an agreement between parents and decision making Local Authorities (LAs). If parents and LAs disagree about the best way to educate their child, many are using the independent Tribunal system as a mechanism to redress their concerns. It is an independent system where parents can appeal decisions made by local authorities regarding their child's educational provision. This has resulted in an increasing number of appeals on behalf of children with named disabilities (SENDIST, 2008); one of which is autism spectrum disorders (ASD). Autistic spectrum disorders are consistently listed as one of the most frequent named disabilities for consideration at the SENDIST as seen in the yearly Annual Reports. There is a steady increase in numbers each year from $13 \%$ of total cases in $1999-2000$ (SENDIST, 2000) to $28 \%$ of cases in $2007-2008$ (SENDIST, 2008). This shows a worryingly upward trend indicating that more and more parents disagree with decisions made by Local Authorities and are unable to reach a compromise. The question is therefore how to support constructive agreement between the two parties.

When focusing on ways forward there are three areas that specifically relate to ASD that contribute to the debate and may influence the journey taken to agree the best way as well as place to provide quality educational provision. These are a personal belief in the underlying philosophy of inclusion and the factors that cause a child's autism; and following on, how these lead to the determination of educational provision. Schools, Local Authorities and parents may have different philosophies about how children are educated which may in part be influenced by personal beliefs and ideals (Croll \& Moses, 2000). For example if a parent believes strongly that mainstream provision is the best place for their child, they may have an unrealistic expectation of what an individual school can provide. Likewise if Local Authorities believe that there is a strong genetic component to a child's ASD, they may find working with a particular family challenging and discount their views. This can potentially create tension and an environment where engaging all stakeholders is difficult (O'Connor, 2008).

Several initiatives have been put in place in England to address these difficulties. One recent initiative is the Lamb Review (DCSF, 2009). Lamb was asked to report on ways to increase parental confidence and engagement with the educational system for parents of children with additional learning needs. It concludes that '...parents need to be listened to more and the system needs to be more ambitious for their children' (p. 1). Additionally, all schools must have a Special Educational Needs Coordinator (SENCO) and specialised training is now a requirement for these individuals. This new SENCO Qualification (TDA, 2009) emphasises the importance of 
working with families and individuals as a core element essential for training quality professionals. Both initiatives are new and therefore it is premature to assess impact. However, to establish evidence of improvement it is equally important to explore the perspectives of two main stakeholders (parents and Local Authorities). This will provide a starting point when looking at further insights at the tensions and dilemmas that exist in the broader social context which impact directly on an individual child and the process of determining quality educational provision for a child.

Previous research shows that parents of children with autism spectrum disorders find the process of agreeing educational provision particularly stressful (Tissot \& Evans, 2006). Schieve et. al. (2007, p. S121) suggest that 'parents or primary caregivers of children with autism may face unique stresses...' when compared to groups of parents of children with other types of developmental needs, and parents of children without additional needs (Parsons, Lewis, \& Ellins, 2009). Research evidence establishes an uncomfortable pattern, but frequently focuses on the views of one group--parents. Although the views of parents are essential to a fuller understanding of the decision making process, they are not the only participant. This research attempts to address this gap and explores the views of both the parent and provider (Local Authority). It is interested in exploring the views of these main stakeholders and how they work together to determine what the appropriated educational provision for a child is. Several methods were used to investigate the views of these two groups, which is primarily comprised of data gained through qualitative methods (research interview and questionnaire). When quantitative methods were used (parental questionnaire) this was due to the desire to capture the views of as many parents as possible (Cohen, Manion, \& Morrison, 2007).

Parental opinion was gathered through the use of a questionnaire. After addressing ethical issues, a questionnaire was piloted, revised and distributed with permission to two national charities, two local charities and 16 specialist schools to distribute to parents of children with ASD, resulting in an opportunity sample of 738 returned surveys (representing an estimated $34.3 \%$ rate of return ${ }^{1}$ ). Most of the items were quantitative in nature with the exception of the last two which were open-ended (Silverman, 2010). This allowed respondents the opportunity to express in their own words their thoughts and reflections on the process of determining educational provision for their child. The majority of respondents had children with a diagnosis

\footnotetext{
${ }^{1}$ Due to ethical considerations, the author did not have access to individual data bases. It is very likely that several parents received multiple copies due to membership in both national and local charities, which would therefore have an impact on the rate of return.
} 
on the autistic spectrum $(96 \%, n=707)$ and statements of special needs for their child $(90 \%$, $\mathrm{n}=645$ ). Of the remaining $10 \%$, most of these children were within the preschool age group or in the assessment process. The sample had children placed in a wide variety of types of settings (see Figure 2). The largest group were in mainstream settings $(27 \%, n=198)$ as would be expected with the government's emphasis on inclusion. What is also interesting is the large number of parents who have children in specialist settings or boarding settings (between 10-19\% of survey respondents for each group). This is important because settings other than mainstream typically take negotiation with Local Authorities and it is this process which is of particular interest to the study. Thus the majority of parents responding had formal recognition from the Local Authority of their child's autism and the need for special educational provision; many of which negotiated this with their LA.

---Insert Figure 1 here---

The view of Local Authority officials was gathered through the use of semi structured interviews (Kvale, 2007). The ten Local Authorities with the greatest number of survey responses to the parental questionnaire were approached requesting permission to interview a senior member of staff. Of those, five granted permission (two were Local Authorities in greater London, two in South East and one in the South West). In each case these were senior members of the Local Authority with specific responsibility for special needs provision. After appropriate ethical considerations and consent was obtained, these interviews were conducted.

Further analysis of the data from these two groups showed areas where there was general agreement and consensus, and other areas where this was less so. This discussion will centre on four key themes that emerge from the data and explore these from the perspectives of both parents and Local Authority senior managers. These themes are: early diagnosis, obtaining provision, working together and finalising the placement.

\section{Theme 1: Early diagnosis}

The first theme explores issues relating to early identification of a child who has an autistic spectrum disorder. Recent research shows that children are being diagnosed earlier (Charman \& Baird, 2002; Tissot, 2003) and the value of early intervention is widely recognised (Jennifer Evans, Castle, Barraclough, \& Jones, 2001; Honda \& Shimizu, 2002). Consequently many parents who receive an early diagnosis wish to access early intervention programmes (McConachie \& Diggle, 2007) as did many of those in the sample. For many parents diagnosis is seen as a key starting point. One parent states, 'It was a battle getting anyone to understand our problems and believe 
that she was something other than 'naughty' (\#539) and one that is often time consuming 'Although it may seem obvious but early diagnosis is essential as process can take a long time.'(\#437). For some this can be quite a lengthy process and delays seen to have consequences.

'It took four years before the LEA to reconise (sic) Robert was autistic. Despite being diagnosed as autistic by a clinical psychologist, a consultant paediatrician and a professor of psychology. Which led to lots of problems in his early years at school.' (\#649).

The link between diagnosis and getting appropriate provision from the Local Authorities' perspective is less clear. 'The diagnosis of autism doesn't tell you anything about the child.' (LA 2). The feeling is that it is one element in gaining a better understanding of a particular child, but can also be an ending point as far as some parents are concerned, or even seen as a 'fashionable diagnosis' (LA 5), meaning that media awareness is increasing the acceptance of this as a disability. This leads to concerns on the part of several LAs. LA 2 felt that it could even '...raise expectations... The only arrangements that are suitable for their child is autistic specialist'. This can place quite a high demand on a limited number of autistic specific places. But others were not so convinced. '...if you have a diagnosis of an autistic spectrum disorder it puts you in a strong position to ask for certain services. So it can be the key to unlocking resources' (LA 5).

The issue also centred on the use of labels to define provision. 'Labels that are given to children hamper us to be honest with you...' (LA 2). There were strong feelings on the issue of early diagnosis and consequently, labelling children. The Local Authorities interviewed expressed the view that a label did not help the LA to define the best type of educational provision. Several shared the view that a label can even deter parents from a provision that can be beneficial, just because the provision is not autistic specific. This is contrast to the view of parents who feel a diagnosis will advance their child's chance of obtaining a specific provision they feel is best suited. Parents perceived this view on the part of the LAs as a delay in an effort to reduce costs. Several were sceptical with one stating '...unless of course in diagnosing child financial implications are incurred' (\#665). This view is often heard by the LAs as they try to match children with provision.

'If you call it SLD, Severe Learning Difficulties, people will believe this [specific school] is right or wrong for their child..[in the parents mind] the child doesn't fit that label, ....it is about trying to overcome barriers...I guess prejudice, we are trying to base decisions on the ability of the child to learn [and not the label]...' (LA 2)

There are mixed feelings on the part of local authorities on the value of early diagnosis. In principle all agree in the merit of obtaining information linked to a particular child which will help in meeting that child's specific educational needs. In some case there is an element of resistance 
as these same authorities see it as a limiting factor and one that can reduce educational options for a particular child. Many are reluctant to label children and resist the attempts of parents to categorise children at often very early stages of their education. The issue of funding also has an impact on this debate from the point of view of both groups. This runs across several themes and is seen as a barrier to getting the provision that parents feel is needed and a key reason why families are eager to obtain a diagnosis.

\section{Theme 2: Agreeing educational provision}

Once there is agreement that the child has additional learning needs, determining the best place to provide for these is not straightforward. In general, parents perceive this as overly bureaucratic and time consuming. 'The system seems to be a lumbering administrative sequence rather than a genuine attempt to meet the needs of the child.' (\#112) and '...to get an educational provision for any autistic child is a nightmare' (\#338). Some parents feel the problems lie with the system:

'Securing provision should be based on matching a child's needs with provisions and finding a placement that will provide. Instead, LEA tends to define child's needs according to what provision is available and cheap.' (\#481)

'The process itself is a long tortuous affair which could be entirely overcome by an interview and brief assessment period instead.' (\#423)

Others feel that the main problem is the lack of resources:

'It is a complete joke to read the government guidelines and assume that a child's needs come first. To the LEA what comes first is: their budgets, their resources, their costs.' (\#410)

Both of these beliefs are recognised by the LAs and efforts are made to address them. One key area to try and reduce bureaucracy is through the reduction in the number of statements issued. All LAs interviewed stated they were moving away from the practice of issuing statements (one reduced the number issued by $85 \%$ (LA 3); citing this as an opportunity to reduce bureaucracy and still be able to deliver educational support to children without the need for a statement. LA 4 stated that it is just as easy to 'put back money as easily as we can remove it'. However, most survey parents don't quite see this point of view. 'Statementing should not be a fight with diagnosis, it is a right' (\#116) and 'It took 13 months to get a proposed statement-typing shortage!' (\#31).

The issue of resources and funding provoked mixed findings from the LAs point of view. Cases are dealt with individually and '...we have some hugely complex, difficult cases ... [but] it wasn't a resources issue ultimately' (LA2). The LAs do have a finite financial supply and those interviewed 
were aware of budgetary constraints. It is therefore unrealistic not to take this into consideration.

Financial limitations are not the only factor for consideration. The government's push for inclusion can be perceived as a limiting factor for some parents as well as local authorities.

'The irony that I see is that in order to maintain some children in mainstream primary school they are having to take them out of the class, in order to manage them. So there may be less social inclusion than you might have in a special school. (LA 5).

Further consideration on this issue causes some interesting ideas on inclusion by both Local Authorities and parents. Is the move towards inclusive provision one that is best for the child or one '...about making ourselves feel better rather than saying this is what the person needs' (LA 5). 'Ideally mainstream is the best because an autistic can emulate normal children' (\# 305) but is it really best for that child? 'The isolation of child and parent in mainstream school is awful.' (\#272).

But this is not the case of all respondents. Several shared their positive experiences and the supportive nature of their LA and the experience of assessing and agreeing provision.

'Ours has been a positive experience. The local authority provided a support worker for the family. A local primary allowed us a trial place in a mainstream nursery as part of the assessment process. Nobody has ever made a 'guesstimate' of our daughter's potential they are only concerned with meeting her needs now and planning [for the future]' (\#548)

How can this be achieved? The next section will look at the views of both groups on the topic of establishing a working relationship.

\section{Theme 3: Working together}

Working together is a desired outcome for both groups but achieving this is often complicated. One consideration is that survey parents found the actual process of obtaining appropriate provision stressful. Using a Likert scale where ' 1 ' represented 'not at all stressful' and ' 5 ' represented 'extremely stressful', $65 \%$ of families responding ( $n=455$, mean 3.8 , SD 1.32 ) said this was a 'very stressful' or 'extremely stressful' process. Figure 3 shows the areas that families found the most stressful.

---Insert Figure 2 here-----

It is interesting to note that parents stated that dealing with LA staff as the most commonly cited area that caused stress when determining appropriate educational provision for their child. This is not unexpected and all of the LAs interviewed seemed to recognise this and were keen to stress their efforts to work collaboratively with parents. 'We need to talk to parents and explain. Communication leads to confidence' and '..we must listen to our customers, how can you not?' (LA 
3). Several examples were given throughout the interviews of how the LAs worked proactively with parents to try and reach agreements.

'I feel very strongly that part of our responsibility is to maintain the dialogue with parents, or at least attempt to. We can't walk away from this.' (LA 2).

But some cases are not straightforward or are quite complex and LAs are faced with difficult decisions. If parents are determined that only one specific type of provision or a specific school will meet their child's needs, then options are limited. Working through these incidents can be trying on the part of the LA.

'You know we do as much as we can. Help parents where we can. But you know there does come a point where ... nothing is going to please parents.' (LA 4).

'Parents become obsessional about a particular approach or a particular school... Clearly for their own child, this is what we believe is right for our child and will not accept any compromise, however suitable.' (LA2).

If no agreement can be reached, then dispute resolution becomes necessary. In England, the SENDIST (Tribunal) is seen as an impartial way to reach agreement between parents and the LA. Of all the themes explored with parents and LAs, this one generated the most diverse responses. Those survey parents, who had experience of the Tribunal, were negative about the experience.

'The first Tribunal named school it had no right to. That school/LEA went to the high court and referred the matter back to the Tribunal.' (\#444)

'They [LAs] waste time, refuse to take action, then you apply to Tribunal they back down at the last moment.' (\#354)

Local Authorities also felt the additional pressure that taking a case to Tribunal can bring. 'I hate the Tribunal process. We should not be putting parents through Tribunals.' (LA 1). She then went on to explain that the cost in terms of staff time was money that should be spent on making provision for the child. Many agreed that it was a waste of resources, but several did feel it could be helpful in getting past difficult disagreements with parents or even a way to justify a particular type of provision that would not normally be sanctioned by the LA. 'You get to a point in certain cases where perhaps... we try and seek an agreement but ultimately let the Tribunal decide.' (LA2).

Working together was seen as a valuable goal on the part of both parents and LAs interviewed, but there was differing views on the role of the Tribunal. Both parents and LAs interviewed recognised the costs involved in preparing a case for a Tribunal and recognised the need to try and avoid this. Agreement is not always easy to reach and in some cases LA officials viewed this as a useful way forward when both sides get to a point where further discussion is deemed fruitless. 


\section{Theme 4: Finalising the placement}

Not all of the survey families have reached an agreement about their child's educational provision. Of those that did, the majority had less than positive statements to make about the process. Often these comments were quite critical and directed at the Local Authority in particular. Further investigation into reasons for this explored the views of parents about the final outcome of the process. Perhaps surprisingly given the findings thus far, almost $80 \%$ of survey parents $(79 \%, \mathrm{n}=584)$ had their child educated in their placement of choice. If the majority of parents reached an agreement with their LA that was what parents wanted, how could the process be viewed so negatively by the majority of survey parents?

For a minority $(36 \%, n=268)$, reaching an agreement was relatively straightforward. Parents stated it was a matter of a simple agreement to determine appropriate provision for their child with ASD. Others found the process as more of 'negotiation' (16\%, $n=119)$, or 'persistent and protracted negotiation' $(24 \%, n=177)$. Twelve per cent found reaching agreement difficult and took their case to the Tribunal or sought other means of support (contacted their Member of Parliament, etc.). Most families relied on their own understanding and initiative to reach an agreement, but for those that accessed outside means of support most were to provide independent reports or advice $(11 \%, n=79)$. Others felt they were left with little alternative, stating that it was difficult to obtain the provision of their choice without specialist help (4\%, $\mathrm{n}=26$ )or felt left with little option as their LA refused to provide a statement or placement that parents felt was appropriate $(3 \%, n=23)$.

If the first choice of parents is the outcome for the large majority of cases, why is simple agreement not cited more often as the means to obtain this? The LAs interviewed cited several factors that add stress to the system. One is seen in the increase in the number of diagnosed children with autism (Baird et al., 2006; MRC, 2001).

"Yes, sometimes it is not easy... we have insufficient number, going back to the pressure of places... let's say we have five vacancies a year at a school. At the last panel we had to discuss [intake for September] we had 62 children...for whom in essence the provision describes as 'autistic specialist' might have been appropriate...' (LA 2).

There is also a tension between striving to provide good quality provision and the increase in demand this brings. One LA described it as both a 'benefit and burden' (LA 2) and another shied away from any external publicity because '...too much publicity...causes a system overflow with parents moving into the area' (LA 3). 
Although proud of their high quality provision, the knock on effect was an increase in demand for this provision. This was not only from parents currently within that authority, but also from families willing to move into the authority, or even from foreign countries.

'...it is a bit like the M25, because we doubled the size of these provisions and where are they all coming from? We have people writing to us from Hong Kong.' (LA 2)

Given the strong views on the part of some parents that the financial cost to a provision is the primary concern on the part of the LA, it is not surprising to see that this is considered, but perhaps not to the extent thought by survey parents. 'The blocks are...having to get through the right channels-and funding; funding comes into it' (LA 4). For several it was more of a matter of philosophical and practical challenges that needed further time and attention, rather than simply a matter of funding. 'Balancing how much [support] is the right amount and how much is intrusive [is a challenge]. How much is too much?' (LA 1). In some cases extra adult support can add an extra layer and 'the adults just suffocate the child, the child's independent learning [suffers]' (LA 4). This process is about making decisions which involve a child. One LA wondered about inclusion as it relates to the wishes of someone with ASD.

'Maybe we are making decisions all the time about what we see as priority about what we see as important. Somewhere underneath I'm wondering if we are peddling the same cultural agenda as someone with ASD [would choose]' (LA 5).

This issue is complex. Although it would be unreasonable to make the assumption that funding and resources are not considered when making decisions about a child's provision, this is not the main issue that many survey parents believe it to be. When reaching a decision about which place is best to provide the quality provision that parents require, delays take place due to the large number of children going through the process, the limited number of specialist places and a real desire to get the process right. This process takes time and this delay is at times difficult for parents to accept given their understandable desire for quality, early intervention.

\section{Discussion}

A tension exists that is built on perceptions. Parents perceive the process of determining and securing educational provision for their child with autism spectrum disorders as time consuming and one that takes prolonged and protracted negotiation with the Local Authority. They are aware of the need for early, effective intervention and feel that spending time debating provision is delaying a needed service for their child. This is causing stress to the majority of survey parents. It is unclear from the research whether it is the 'anticipated' disagreement or an 'experienced' disagreement which is causing this, as most families reached their intended goal. Is this due to the additional effort and time on the part of families (or involvement of outside 
experts) or is it despite this? Families see this level of involvement as a necessity to get their preferred outcome and celebrate this success, but not the process.

Local Authorities also see this tension. They are aware of the stresses families are under and they work hard towards establishing a partnership with parents. Most were realistic about not being able to please every parent, but felt confident in meeting the needs of every child and including parents in the process. Those interviewed shared their desire towards inclusive practice but often debated the meaning of that for an individual child. Delays or disagreements with parents add to the perceived tension.

The tension also extends to the definition of what the determined provision means in practice. Resources were often part of this debate. Parents felt delays in making decisions were due in large part to unwillingness on the part of the LA to spend money. This may be simplistic, as often other issues needed to be considered such as how to balance support with a desire for the child to reach levels of independence.

It is easy to make broad judgements that Local Authorities are making the process time consuming and are resisting parental efforts to come to a consensus. This appears to be the case for a limited number of survey respondents and a real experience for those families. These are the cases that get shared among groups of parents and contribute to an already anxious and stressful time thus feeding the levels of tension (perceived or real) on the part of this group. But as the majority do reach an agreement which is the first choice of the parent, what is it about that message that is not getting through? The answer to that question needs to focus more on the process. Part of that discussion is a realistic look at the expectations of parents and a closer look at how Local Authorities work with families.

Inclusion is not the only answer, although it is the most frequent the answer. Parents are often anxious early in the process of determining provision due to fears of not getting the process right and worries that mainstream provision may be the default for all and not necessarily the best choice for their child. Parents often feel that autistic specialist provision is the best match for their child with autism and are not confident that their child is suited for mainstream settings. They want guarantees on levels of support and often feel the only way to get this is by obtaining a Statement of Special Educational Need (DfES, 2001) from the Local Authority. Delays in finalising an agreement and limited places at specialist settings cause an uneasy anxiety for parents. This 
anxiety builds into a view that mainstream provision is an easy choice on the part of the Local Authority and is mainly used as a cost saving exercise. Although limiting costs is not the priority that parents perceive it to be, it is still a factor and one that needs addressing in order for parents to gain confidence in this type of provision.

This tension is recognised by the government and is one of the reasons that the recent Lamb Review (DCSF, 2009) looked at ways to address parental confidence in SEN provision. The need for greater levels of communication is key theme running throughout both the report and the government's response (DCSF, 2010).

How do practitioners increase the confidence of parents in meeting the educational needs of students with disabilities? The findings of this research point to a tension that is shared by a great number of parents of children with autistic spectrum disorders on how to get what they see as the right provision for their child. They come to the process of negotiation with high expectations that the process is not going to be easy and often have a formed opinion on what the acceptable outcome will be. Any resistance to agree that conclusion is seen to be a matter generally related to resources. It is not realistic to ask Local Authorities to have an unlimited purse in this current climate of economic restraint. They have the responsibility to see the bigger picture and are often asking hard questions, and parents are advocates for their children. Parents find it difficult to accept any limitations that they perceive as having a restraining factor on their child's future. Is the current system transparent enough? Is it reasonable to ask parents to accept alternatives to what they see as the one provision that is right for their child? Until we can move forward on these two questions, the diverse nature of autism and the increasing number of children with this disability mean that we will not move closer to making this a straightforward process of working together to determine the best way to meet a child's educational needs. 


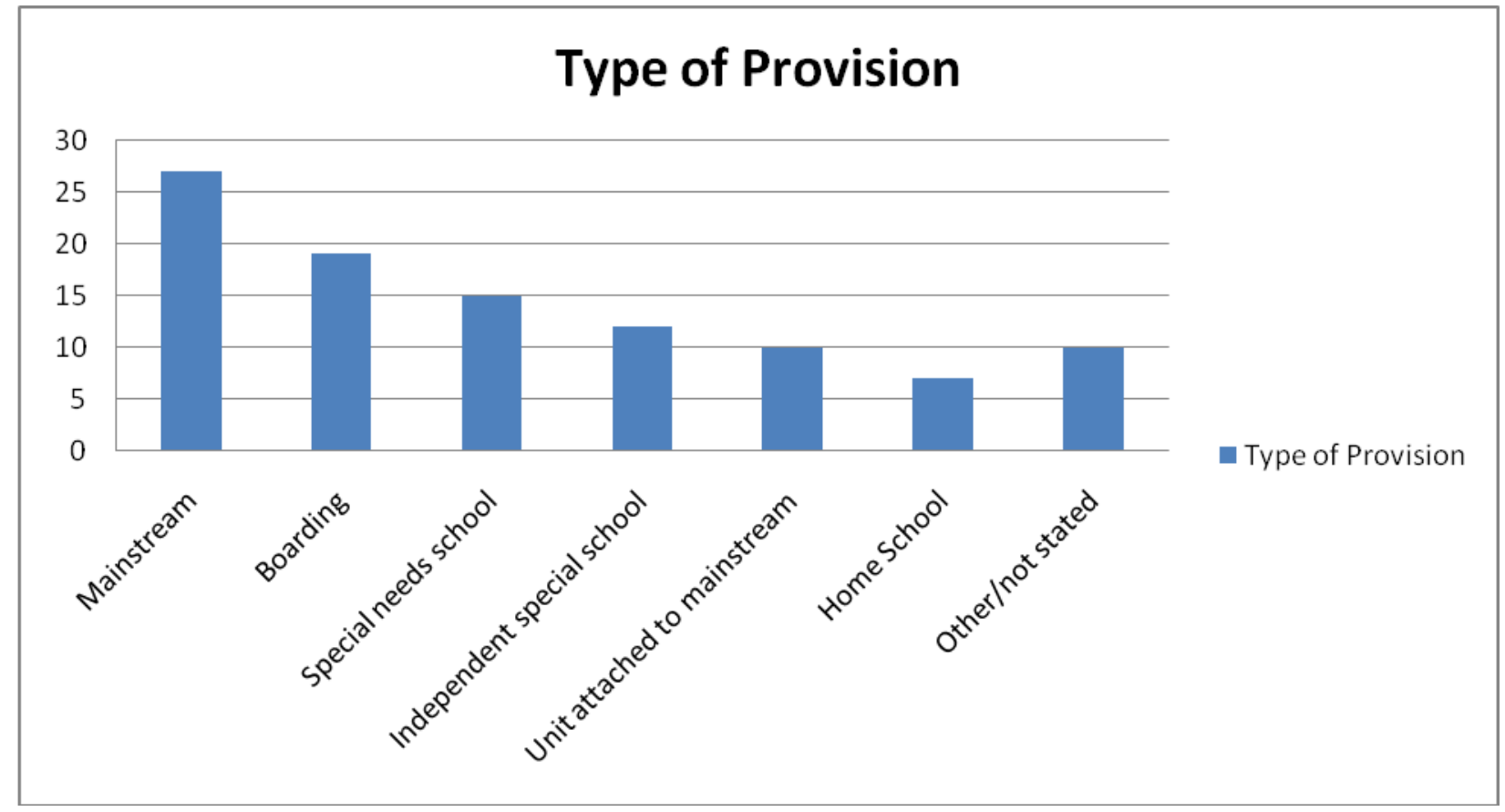

Figure 1: Type of provision 


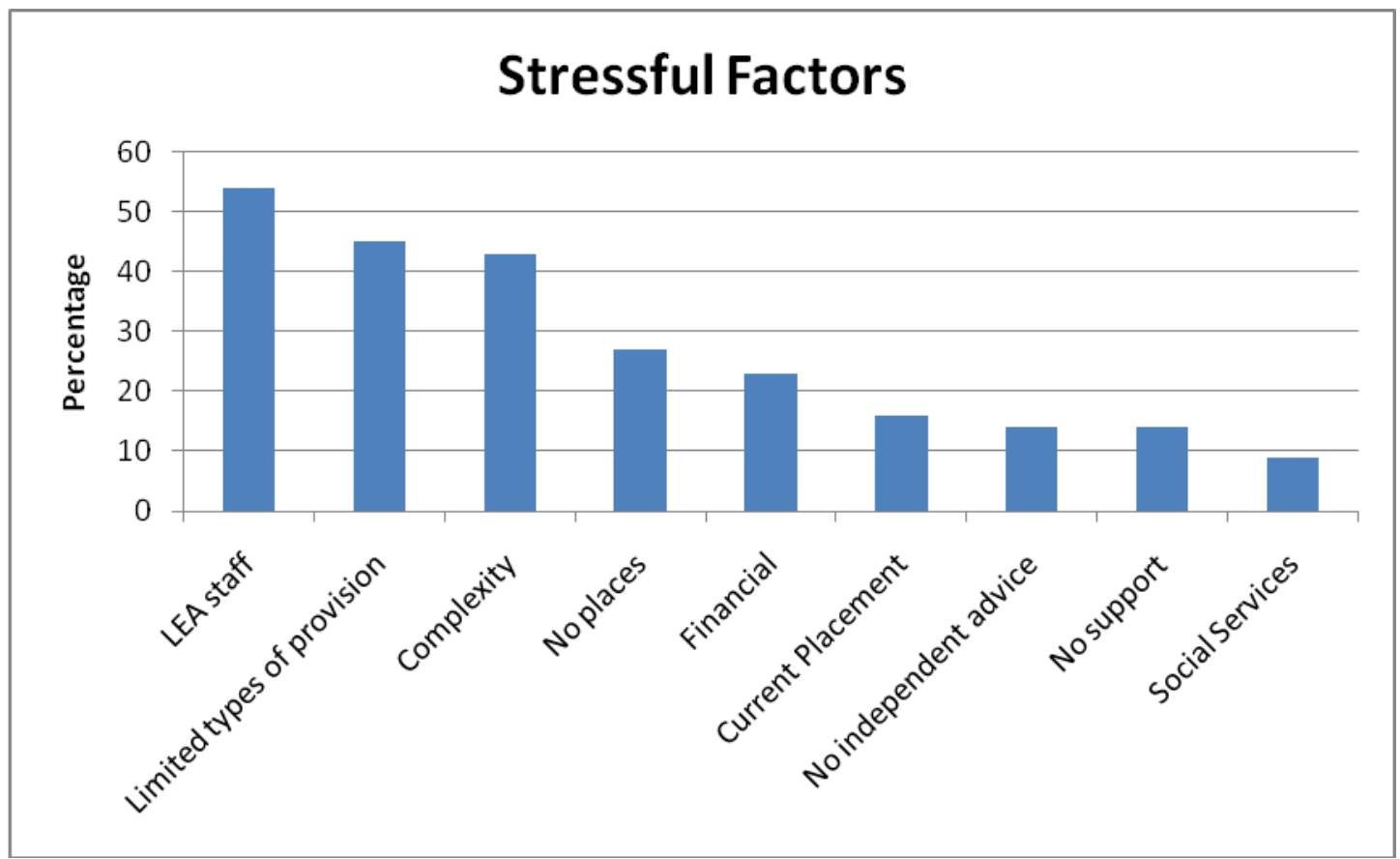

Figure 2: Factors that sample families find stressful 
References:

Baird, G., Simonoff, E., Pickles, A., Chandler, S., Loucas, T., Meldrum, D., et al. (2006). Prevalence of disorders of the autism spectrum in a population cohort of children in South Thames: The Special Needs and Autism Project (SNAP). Lancet, 368(210-215).

Charman, T., \& Baird, G. (2002). Practitioner Review: Diagnosis of autism spectrum disorder in 2and 3-year-old children. Journal of Child Psychology and Psychiatry, 43(3), 289-305.

Cohen, L., Manion, L., \& Morrison, K. (2007). Research Methods in Education (6th Edition ed.). London: RoutledgeFalmer.

Croen, L., Grether, J., Hoogstrate, J., \& Selvin, S. (2002). The Changing prevalence of autism in California. Journal of Autism and Developmental Disorders, 32(3), 207-215.

Croll, P., \& Moses, D. (2000). Ideologies and utopias: education professionals' views of inclusion. European Journal of Special Needs Education, 15(1), 1 - 12.

DCSF. (2009). Lamb Inquiry: Special educational needs and parental confidence. Annesley, Nottingham.

DCSF. (2010). Improving Parental Confidence in the Special Educational Needs System: An implementation plan. Annesley, Nottingham: Crown Copyright.

DfES. (2001). Special Educational Needs Code of Practice. Annesley, Nottinghamshire: DfES Publications.

Evans, J., Castle, F., Barraclough, S., \& Jones, G. (2001). Making a Difference: Early Interventions for Children with Autistic Spectrum Disorders (No. 22). London: Local Government Associationo. Document Number)

Evans, J., \& Lunt, I. (2002). Inclusive education: Are there limits? European Journal of Special Needs Education, 17(1), 1-14.

Ferguson, D. (2008). International trends in inclusive education: the continuing challenge to teach each one and everyone. European Journal of Special Needs Education, 23(2), 109120.

Honda, H., \& Shimizu, Y. (2002). Early intervention system for preschool children with autism in the community: the DISCOVERY approach in Yokohama, Japan. Autism, 6(3), 239-257.

Kanner, L. (1943). Early infantile autism. Journal of Pediatrics, 25, 211-217.

Kvale, S. (2007). Doing Interviews. London: Sage Publications.

McConachie, H., \& Diggle, T. (2007). Parent implemented early intervention for young children with autism spectrum disorder: a systematic review. Journal of Evaluation in Clinical Practice, 13, 120-129.

Mittler, P. (2008). Planning for the 2040s: everybody's business. British Journal of Special Education, 35(1), 3-10.

MRC. (2001). MRC Review of Autism Research: Epidemiology and Causes. London: Medical Research Councilo. Document Number)

No Child Left Behind Act, US Department of Education(2007).

Norwich, B. (2008). Dilemmas of difference, inclusion and disability: international perspectives on placement. European Journal of Special Needs Education, 23(4), 287-304.

O'Connor, U. (2008). Meeting in the middle? A study of parent-professional partnerships. European Journal of Special Needs Education, 23(3), 253 - 268.

Parsons, S., Lewis, A., \& Ellins, J. (2009). The views and experiences of parents of children with autistic spectrum disorder about educational provision: comparisons with parents of children with other disabilities from an online survey. European Journal of Special Needs Education, 24(1), 37 - 58.

Plant, K. M., \& Sanders, M. R. (2007). Predictors of care-giver stress in families of preschool aged children with developmental disabilities. Journal of Intellectual Disability Research, 51(2), 109-124. 
Rice, C. (2009). Prevalence of autism specturm disorders---Autism and Developmental Disabilities Monitoring Network, United States, 2006. Morbidity and Mortality Weekly Report 58(SS10), 1-20.

Rogers, C. (2007). Experiencing an 'inclusive' education: parents and their children with 'special educational needs'. British Journal of Sociology of Education, 28(1), 55 - 68.

Schieve, L. A., Blumberg, S. J., Rice, C., Visser, S. N., \& Boyle, C. (2007). The Relationship Between Autism and Parenting Stress. Pediatrics, 119(Supplement_1), S114-121.

SENDIST. (2000). Special Educational Needs and Disability Tribunal Annual Report 1999-2000. Sudbury, Suffolk: Crown Copyright.

SENDIST. (2008). Special Educational Needs and Disability Tribunal (SENDIST)

Silverman, D. (2010). Doing Qualitative Research. London: Sage.

Spann, S., Kohler, F., \& Soenksen, D. (2003). Examining parents' involvement in and perceptions of special education services: An interview with families in a parent support group. Focus on Autism and Other Developmental Disabilities, 18(4), 228-237.

TDA. (2009). Specification for nationally approved training for special educational needs coordinators (SENCOs) new to the role, leading to the award of the National Award for SEN Coordination: http://www.tda.gov.uk/upload/resources/pdf/s/national senco training specification.p $\underline{\mathrm{df}}$

Tissot, C. (2003). Investigation into Factors Associated with the Provision of Effective Education for Chidren with Autistic Spectrum Disorders. Brunel University, Middlesex.

Tissot, C., \& Evans, R. (2006). Securing provision for children with autistic spectrum disorders: The views of parents. Perspectives in Education, 24(1), 73-86.

Treffert, D. (1970). Epidemiology of infantile autism. Archives of General Psychiatry, 22(431-438).

UNESCO. (1994). The Salamanca Statement and Framework on Special Needs Education. Paris: UNESCO.

Wedell, K. (2008). Confusion about inclusion: patching up or system change? British Journal of Special Education, 35(3), 127-135. 